Journal Club

Editor's Note: These short reviews of recent JNeurosci articles, written exclusively by students or postdoctoral fellows, summarize the important findings of the paper and provide additional insight and commentary. If the authors of the highlighted article have written a response to the Journal Club, the response can be found by viewing the Journal Club at www.jneurosci.org. For more information on the format, review process, and purpose of Journal Club articles, please see http://jneurosci.org/content/ preparing-manuscript\#journalclub.

\title{
Estradiol Modulates Hemispheric Lateralization of Auditory Evoked Neural Activity in Male European Starlings (Sturnus vulgaris)
}

\author{
이ake V. Aronowitz, ${ }^{1}$ Kristena L. Newman, ${ }^{2}$ and Courtney R. McDermott ${ }^{3}$ \\ ${ }^{1}$ Master's in Behavioral Neuroscience Program, Queens College of the City University of New York, Flushing, New York 11367, ${ }^{2}$ Department of Psychology, \\ The Graduate Center, City University of New York, New York, New York 10016, and ${ }^{3}$ Department of Psychology, Queens College of the City University of \\ New York, Flushing, New York 11367 \\ Review of De Groof et al.
}

Songbirds use learned vocalizations to communicate with conspecifics; predominantly to defend their territory and attract mates (Eens, 1997). Interestingly, in some songbirds, including European starlings (Sturnus vulgaris), the brain regions underlying song production and perception undergo dramatic physical changes throughout the year. Seasonal transitions from nonbreeding to breeding conditions, along with marked changes in steroid hormone levels, accompany these anatomical changes. For instance, the caudomedial nidopallium (NCM), which is functionally homologous to mammalian auditory association areas (Yanagihara and Yazaki-Sugiyama, 2016), increases in volume during the breeding season (De Groof et al., 2009).

Steroid hormones, including testosterone and $17 \beta$-estradiol, act centrally in the songbird telencephalon (Riters et al., 2001) and may contribute to seasonal changes in song substrates. Traditionally, estradiol and other steroid hormones were thought

Received May 23, 2017; revised July 11, 2017; accepted July 15, 2017. The authors declare no competing financial interests.

Correspondence should be addressed to Jake V. Aronowitz, Master's in

Behavioral Neuroscience Program, Queens College of the City University of New York, Flushing, NY 11367. E-mail: jakearonowitz@gmail.com.

DOI:10.1523/JNEUROSCI.1414-17.2017

Copyright $\odot 2017$ the authors $\quad 0270-6474 / 17 / 377800-03 \$ 15.00 / 0$ to function solely via actions at nuclear receptors, ultimately affecting gene transcription (Schumacher, 1990). However, accumulating evidence suggests a more rapid, membrane-mediated effect of estradiol in the CNS (Remage-Healey et al., 2011). For example, intracerebral introduction of exogenous estradiol rapidly increased responsivity of auditory neurons in NCM (Tremere et al., 2009), and acute blockade of estradiol synthesis in the brain decreased burst firing in NCM (Remage-Healey et al., 2010). Having previously demonstrated (De Groof et al. 2013) that NCM responsivity to different auditory stimuli changes seasonally, De Groof et al. (2017) asked whether the role of estradiol in auditory processing changes depending upon the season/photoperiod and breeding condition.

Wild-caught, adult male European starlings underwent fMRI while listening to audio recordings of songs or pure tones during three seasons: winter (December, nonbreeding), early spring (March, breeding), and summer (May/June, nonbreeding). After the first imaging session in December, light/dark cycles were adjusted weekly to mimic natural changes in photoperiodicity. During each imaging session, the authors compared NCM responsivity before (baseline) and after blocking estradiol synthesis using systemic injections of vorozole, an aromatase inhibitor that substantially reduces levels of estradiol within 30 min (Cornil et al., 2006). The authors found that estradiol depletion reduced NCM responsivity to auditory stimuli. Furthermore, this effect was more pronounced in the early spring (breeding season). In the third fMRI session (May/ June), the researchers confirmed that estradiol was indeed the factor giving rise to differences in NCM activity between baseline and estradiol-depleted conditions. To do this, they followed the estradiol depletion session with a systemic injection of estradiol, and then replayed the stimuli while recording NCM activity. They found that administration of exogenous estradiol increased responsivity of the NCM/Field L/and caudomedial mesopallium (CMM) auditory complex bilaterally, but in a manner that was stimulus-type-specific.

De Groof et al. (2017) used three types of auditory stimuli varying in signal content and context: species-specific warbling (SPEC), which is a part of the vocalizations of all male starlings; individual warbling (INDIV), which consists of syllables specific to individual conspecifics; and pure tones (PT), a control stimulus. SPEC and INDIV 
stimuli differ in salience depending upon the season and social conditions. For instance, during the nonbreeding season, one function of singing behavior is social cohesion within a large flock (Eens, 1997): birdsong can be a social marker used to indicate belongingness to a group (Feekes, 1977). Indeed, birds with the same dialectal variants of song, indicative of similar geographic origin, tend to group together in large roosts (Hausberger et al., 2008). However, during the breeding season when levels of circulating steroid hormones are high (Tramontin et al., 2003) singing is used in mate attraction (Gentner and Hulse, 2000) and territory defense (Eens, 1991). If estradiol plays a role in regulating NCM responsivity to songs and is higher during the breeding season than the nonbreeding season, one would expect that blocking estradiol would result in a greater decrement in NCM responsivity, relative to baseline, during the breeding season.

Interestingly, in addition to seasonal changes in responsivity, the authors showed seasonal changes in hemispheric lateralization of BOLD responses. Relative to baseline conditions, estradiol depletion substantially decreased neural activation during the breeding season (March) within the left NCM/Field L/CMM auditory complex, but not in the right hemisphere (De Groof et al., 2017). This is consistent with previous findings in the zebra finch that the left NCM plays a larger role in auditory discrimination than the right NCM (Remage-Healey et al., 2010). Lateralization of function in NCM/Field L/CMM may underlie finely-tuned processing of conspecific vocalizations, which in turn affects social behavior. The authors speculate that seasonal changes in the degree of hemispheric lateralization of BOLD response may be mediated by seasonal changes in aromatase distribution within the forebrain. To test this, they measured bilateral aromatase activity in these same birds in January, six months after the final fMRI session. They looked for hemispheric differences in aromatase activity in NCM, CMM, and the hypothalamic preoptic area. They did not find any hemispheric differences in aromatase activity and suggested that this may be due to the fact that the assay was performed in the nonbreeding season, when lateralization of the BOLD response was not present. Future studies might be constructed such that a subset of birds is tested during breeding conditions to determine whether hemispheric differences in aromatase activ- ity are present at the time of lateralized BOLD levels.

Previous work showed that hemispheric lateralization of activity in NCM varies as a function of the auditory environment (Yang and Vicario, 2015). In their study, Yang and Vicario (2015) used two measures to quantify electrophysiological population recordings in NCM in response to auditory stimuli: absolute response magnitude, which is the strength of neural responses, and adaptation rate, the rate of decline in responding to repeated presentation of a stimulus. Control birds housed individually were exposed to a playback of a conspecific auditory environment (zebra finch aviary sounds) for 2, 4, or 9 d. Response magnitudes were higher and adaptation rates were faster in the right hemisphere (Yang and Vicario, 2015). However, adult male zebra finches exposed exclusively to playbacks of a heterospecific auditory environment (canary aviary sounds) for the same durations displayed a marked reversal of hemispheric lateralization in response to zebra finch songs, with higher response magnitudes and faster adaptation rates in the left hemisphere. One interpretation of this result is that the degree of hemispheric lateralization in NCM is influenced by the demands of the environment. As the environment changes, organisms must adapt, and this applies not only to overt behaviors, but to perceptual processes as well. Behavioral flexibility across breeding seasons requires perceptual plasticity. Male starlings sing at a high rate throughout the year, demonstrating that song can have different meanings depending upon the exact content and context (Feekes, 1977; Feare, 1984; Eens, 1997). During the breeding season, starlings reside in small groups of mating pairs, dramatically changing the auditory environment from the large flocks of the nonbreeding season (De Groof et al., 2013). In breeding conditions, it may be more important to identify individuals by their auditory signature permitting discrimination between rivals, mates, and other ecologically relevant identities. Therefore, increased left-dominance of estradiol-modulated NCM activity during the breeding season, specifically in response to INDIV but not SPEC stimuli, may increase the efficiency with which starlings process conspecific vocalizations, perhaps providing a selective advantage.

In summary, the study by De Groof et al. (2017) revealed that estradiol modulates neural activity with respect to photoperiod in the songbird auditory forebrain and demonstrated that aromatase inhibition and the resultant decrease in estradiol levels can have large effects on auditory processing, even in the presence of stable levels of testosterone. Despite the close interrelationship between estradiol and testosterone, this study suggests that the two may have independent effects within the auditory forebrain, perhaps because of localization of receptors on different neuronal populations. Future studies can further assess the independent characteristics of steroid actions in sensory processing, and assess the role of steroid hormones in seasonally dependent changes in neural activation. Finally, these findings provide a neuroanatomical map for future studies endeavoring to understand the functional importance of subregions of the NCM.

\section{References}

Cornil CA, Taziaux M, Baillien M, Ball GF, Balthazart J (2006) Rapid effects of aromatase inhibition on male reproductive behaviors in the Japanese quail. Horm Behav 49: 45-67. CrossRef Medline

De Groof G, Verhoye M, Poirier C, Leemans A, Eens M, Darras VM, Van der Linden A (2009) Structural changes between seasons in the songbird auditory forebrain. J Neurosci 29:13557-13565. CrossRef Medline

De Groof G, Poirier C, George I, Hausberger M, Van der Linden A (2013) Functional changes between seasons in the male songbird auditory forebrain. Front Behav Neurosci 7:196. CrossRef Medline

De Groof G, Balthazart J, Cornil CA, Van der Linden A (2017) Topography and lateralized effect of acute aromatase inhibition on auditory processing in a seasonal songbird. J Neurosci 37:4243-4254. CrossRef Medline

Eens M (1997) Understanding the complex song of the European starling: an integrated ethological approach. Adv Study Behav 26:355434. CrossRef

Eens M, Pinxten R, Verheyen RF (1991) Male song as a cue for mate choice in the European starling. Behaviour 116:210-238. CrossRef

Feare CJ (1984) The starling. Oxford, UK: Oxford UP.

Feekes F (1977) Colony-specific song in the Cacicus cela (Icteridae, Aves): the password hypothesis. Ardea 65:197-202.

Gentner TQ, Hulse SH (2000) Female European starling preference and choice for variation in conspecific male song. Anim Behav 59:443458. CrossRef Medline

Hausberger M, Bigot E, Clergeau P (2008) Dialect use in large assemblies: a study in European starling Sturnus vulgaris roosts. J Avian Biol 39:672-682.

Remage-Healey L, Coleman MJ, Oyama RK, Schlinger BA (2010) Brain estrogens rapidly strengthen auditory encoding and guide song preference in a songbird. Proc Natl Acad Sci U S A 107:3852-3857. CrossRef Medline

Remage-Healey L, Saldanha CJ, Schlinger BA (2011) Estradiol synthesis and action at the 
synapse: evidence for "synaptocrine" signaling. Front Endocrinol 2:28. CrossRef Medline

Riters LV, Baillien M, Eens M, Pinxten R, Foidart A, Ball GF, Balthazart J (2001) Seasonal variation in androgen-metabolizing enzymes in the diencephalon and telencephalon of the male European starling (Sturnus vulgaris). J Neuroendocrinol 13:985-997. CrossRef Medline

Schumacher M (1990) Rapid membrane effects of steroid hormones: an emerging concept in neuroendocrinology. Trends Neurosci 13: 359-362. CrossRef Medline

Tramontin AD, Wingfield JC, Brenowitz EA (2003) Androgens and estrogens induce seasonal-like growth of song nuclei in the adult songbird brain. J Neurobiol 57:130140. CrossRef Medline

Tremere LA, Jeong JK, Pinaud R (2009) Estradiol shapes auditory processing in the adult brain by regulating inhibitory transmission and plasticity-associated gene ex- pression. J Neurosci 29:5949-5963. CrossRef Medline

Yanagihara S, Yazaki-Sugiyama Y (2016) Auditory experience-dependent cortical circuit shaping for memory formation in bird song learning. Nat Commun 7:11946. CrossRef Medline

Yang LM, Vicario DS (2015) Exposure to a novel stimulus environment alters patterns of lateralization in avian auditory cortex. Neuroscience 285:107-118. CrossRef Medline 